\title{
Adhesion Is Prerequisite, But Alone Insufficient, to Elicit Stem Cell Pluripotency
}

\author{
Phillip Karpowicz, ${ }^{1}$ Tomoyuki Inoue, ${ }^{2}$ Sue Runciman, ${ }^{2}$ Brian Deveale, ${ }^{2}$ Raewyn Seaberg,, 2 Marina Gertsenstein, ${ }^{3}$ \\ Lois Byers, ${ }^{3}$ Yojiro Yamanaka, ${ }^{3}$ Sandra Tondat, ${ }^{3}$ John Slevin, ${ }^{3}$ Seiji Hitoshi, ${ }^{4}$ Janet Rossant, ${ }^{3}$ and Derek van der Kooy ${ }^{2}$ \\ ${ }^{1}$ Institute of Medical Science, University of Toronto, Toronto, Ontario, Canada M5S 1A8, ${ }^{2}$ Department of Molecular and Medical Genetics, University of \\ Toronto, Toronto, Ontario, Canada M5S 3E1, ${ }^{3}$ Samuel Lunenfeld Research Institute, Mount Sinai Hospital, Toronto, Ontario, Canada M5G 1X5, and \\ ${ }^{4}$ National Institute for Physiological Sciences, Okazaki, Aichi, 444-8585, Japan
}

Primitive mammalian neural stem cells (NSCs), arising during the earliest stages of embryogenesis, possess pluripotency in embryo chimera assays in contrast to definitive NSCs found in the adult. We hypothesized that adhesive differences determine the association of stem cells with embryonic cells in chimera assays and hence their ability to contribute to later tissues. We show that primitive NSCs and definitive NSCs possess adhesive differences, resulting from differential cadherin expression, that lead to a double dissociation in outcomes after introduction into the early- versus midgestation embryo. Primitive NSCs are able to sort with the cells of the inner cell mass and thus contribute to early embryogenesis, in contrast to definitive NSCs, which cannot. Conversely, primitive NSCs sort away from cells of the embryonic day 9.5 telencephalon and are unable to contribute to neural tissues at midembryogenesis, in contrast to definitive NSCs, which can. Overcoming these adhesive differences by E-cadherin overexpression allows some definitive NSCs to integrate into the inner cell mass but is insufficient to allow them to contribute to later development. These adhesive differences suggest an evolving compartmentalization in multipotent NSCs during development and serve to illustrate the importance of cell- cell association for revealing cellular contribution.

Key words: neural stem cell; plasticity; transplantation; adhesion; cell fate; differentiation

\section{Introduction}

Neural stem cells (NSCs) arise during the earliest stages of embryonic development and persist in the mouse into adulthood (Fig. 1). Leukemia inhibitory factor (Lif)-dependent primitive NSCs can be derived from embryonic stem cells (ESCs) or dissected from the early epiblast (Tropepe et al., 2001; Hitoshi et al., 2004). These give rise to fibroblast growth factor (FGF)dependent NSCs, which, in turn, give rise to epidermal growth factor (EGF)-dependent NSCs, and both of these can be derived from germinal regions of the brain throughout the lifetime of the animal (Morshead et al., 1994; Chiasson et al., 1999). This characterized lineage suggests that primitive NSCs, whose repertoire of descendants includes FGF and EGF dependents, would be thus more potent than their progeny. Indeed, like ESCs, primitive NSCs can differentiate into all three germ layers, suggesting that they retain properties of earlier pluripotent cells (Tropepe et al., 2001), whereas adult NSC progeny demonstrate functional contribution when injected into the forebrain ventricles of adult mice (Herrera et al., 1999).

Received Jan. 23, 2007; revised March 19, 2007; accepted April 7, 2007.

This work was supported by the Canadian Institutes of Health Research. We thank Lee Adamson for the use of the ultrasound injection apparatus, Jorge Cabezas for his assistance with the mouse colony, and members of the van der Kooy laboratory for their insightful comments regarding the draft of this manuscript.

Correspondence should be addressed to Phillip Karpowicz, Institute of Medical Science, Department of Molecular and Medical Genetics, 160 College Street, 11th Floor Donnelly Centre for Cellular and Biomolecular Research Building, University of Toronto, Toronto, Ontario, Canada M5S 3E1. E-mail: phillip.karpowicz@utoronto.ca.

DOI:10.1523/JNEUROSCI.0300-07.2007

Copyright $\odot 2007$ Society for Neuroscience $\quad$ 0270-6474/07/275437-11\$15.00/0
Several studies have indicated that SCs arising in later developmental periods may have pluripotency approaching that of the earliest pluripotent cells. The assessment of potency or transdetermination has been a straightforward categorization of the progeny of cells by their expression of lineage markers. It has been argued that blood SCs are competent to produce a variety of nonhematopoietic cell types (Krause et al., 2001), including neural cells (Brazelton et al., 2000; Mezey et al., 2000). In addition, adult NSCs have been claimed to contribute to blood cell types (Bjornson et al., 1999) as well as endothelial cells (Wurmser et al., 2004). These data are remarkable, because such cell types are sequestered from their respective germ layers early in embryonic development. Some studies have gone so far as to suggest a generalized pluripotency to adult NSCs (Clarke et al., 2000) and SCs derived from the adult bone marrow (Jiang et al., 2002) rivaling that of ESCs. However, the contribution of adult NSCs to early embryogenesis has not been replicated (Tropepe et al., 2001; D'Amour and Gage, 2003; Greco et al., 2004), and the claims of plasticity of blood SCs have been cast into doubt (Wagers et al., 2002). In particular, it is now known that cellular fusion events may confound these reports of potency (Terada et al., 2002; Ying et al., 2002; Alvarez-Dolado et al., 2003; Wang et al., 2003). Thus, it remains unclear whether SCs can retain pluripotency into the adult stages of the life cycle of the animal.

A confounding factor in studying plasticity is the correct association of SC with a tissue, via compatible cell adhesion pathways. In transplantation assays into adult and embryonic hosts 


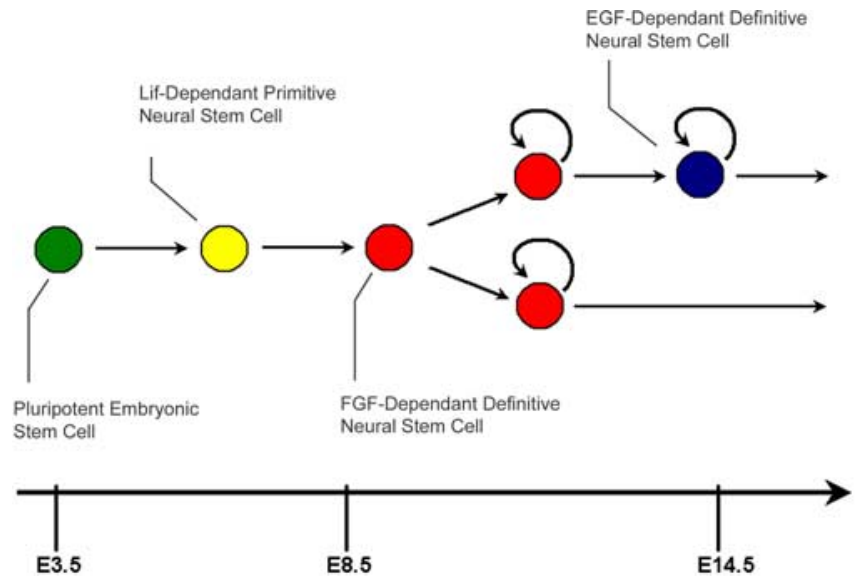

Figure 1. The neural stem cell lineage. Beginning at E5.5, Lif-dependent primitive NSCs (yellow) arise from the early epiblast and transition into FGF-dependent definitive NSCs by E8.5 (red). These, in turn, give rise to EGF-dependent definitive NSCs (blue) at time points past E13.5, and both definitive NSC types continue to self-renew for the lifetime of the animal.

used to assess SC potency, cells are assumed to persist in the tissues into which they are transplanted, so that comparative assessment of contribution from different cell types is solely a product of the ability of SCs to generate multiple differentiated cell types. However, the role of cell-cell association via adhesion is an understood mechanism in the compartmentalization and morphogenesis of tissues during development (Edelman, 1984; Takeichi, 1995). Molecular adhesion is responsible for the sequestration of cells into different tissue germ layers and the intercellular affinity of cells within a tissue. The differential adhesion of cells via cell adhesion molecules results in the sorting of cells into thermodynamically favorable structures (Foty and Steinberg, 2005) that maximize both homophilic adhesions over heterophilic adhesions (Nose et al., 1988) and stronger homophilic adhesions over weaker ones (Steinberg and Takeichi, 1994). In this way, cells are sequestered into distinct compartments of the embryo, sometimes corresponding to distinct molecular programs between the cells in these regions (Matsunami and Takeichi, 1995; Inoue et al., 2001). Therefore, it is formally possible that a pluripotent SC might possess the ability to produce multiple cell types within a compartment provided that it remains in association with that compartment. Both studies suggesting plasticity and those failing to report plasticity, mentioned above (Bjornson et al., 1999; Brazelton et al., 2000; Clarke et al., 2000; Mezey et al., 2000; Tropepe et al., 2001; Jiang et al., 2002; Wagers et al., 2002; D'Amour and Gage, 2003; Greco et al., 2004), have in no case taken into account cell-sorting phenomena in the interpretation of their results.

We hypothesized that SC pluripotency declines as ontogeny advances. Primitive NSCs were predicted to possess greater potency than adult NSCs. However, adult FGF-dependent NSCs and those derived from the embryonic day 9.5 (E9.5) embryo were predicted to possess equivalent potency, because adult FGFdependent NSCs persisting in the adult were self-renewing progeny arising at E9.5 and maintained as such in the adult. Our results confirm these predictions. We also predicted that adhesion-mediated compartmentalization is necessary to elicit SC contribution. This was indeed the case, because early NSCs with the potency to generate neural lineages in vitro were unable to do so if introduced into the brain compartment without a prerequisite associative ability. In contrast, adult and midembryonic NSC types are able to contribute in these same assays. When introduced into preimplantation-stage embryos, it is now the early NSCs that are able to associate and thus contribute, whereas the later NSCs, as well as SCs isolated from the adult retina, cannot. Overcoming such adhesive discrepancies by the overexpression of the appropriate adhesion protein is, however, insufficient to overcome this dearth of contribution. Adult NSCs that are experimentally induced to integrate with the inner cell mass of the preimplantation embryo, via E-cadherin overexpression, are nonetheless unable to contribute to early embryogenesis. These results suggest that appropriate cell-cell adhesion is necessary to allow NSCs to demonstrate their differentiative potential in vivo. However, restriction of potency is not directly related to restriction in cell-adhesive interactions but a fundamental property of maturing NSCs. We thus suggest that adhesion and potency mechanisms exist as parallel but discrete programs in NSCs during development.

\section{Materials and Methods}

Dissection and cell culture. CD1 mice, cyan fluorescent protein (CFP) mice, enhanced yellow fluorescent protein (eYFP) mice or embryos, or dsRed-MST mice were dissected, and their NSCs were cultured as described previously for (1) E9.5 embryonic forebrain ventricles (Tropepe et al., 1999); (2) adult mouse forebrain ventricles (Reynolds et al., 1992; Morshead et al., 1994); (3) primitive NSCs (Tropepe et al., 2001); and (4) retinal SCs (Tropepe et al., 2000). Cells were grown for 1 week before use. $\mathrm{R} 1$ or eYFP ESCs were grown on mitotically inactivated fibroblasts as described previously (Nagy et al., 2002).

Cell-sorting assays. Cells were dissociated mechanically, except for ESCs, which were dissociated using trypsin as described previously (Nagy et al., 2002). Two populations of interest were mixed in equal parts at a total density of 300 cells/ $\mu \mathrm{l}$ in media containing growth factors needed for the survival of both groups of cells used. One milliliter of such cell suspensions was cultured in 24-well plates (Nunclon; Thermo Fisher Scientific, Rochester, NY) on a shaker at $37^{\circ} \mathrm{C}$, overnight. Telencephalic E9.5 cells were dissected immediately preceding cell sorting as described previously (Tropepe et al., 1999). Aggregates were examined by fluorescence microscopy $1 \mathrm{~h}$ after mixing to confirm random distribution of cell populations. Aggregates were then examined after overnight incubation.

Embryoid bodies. Adult NSC colonies and ESCs were cocultured in equal parts using the hanging drop embryoid body formation technique (Dang et al., 2002). Briefly, 30,000 cells were aggregated in 15\% fetal calf serum (HyClone, Logan, UT) as hanging drops for $2 \mathrm{~d}$. Aggregates were then cultured at $37^{\circ} \mathrm{C}$, on uncoated plates (Falcon, Franklin Lakes, NJ) using a shaker, for an additional 2-5 d. Aggregates were collected and allowed to settle to the bottom of conical test tubes (Falcon) by gravitation before fixation using $2 \%$ paraformaldehyde (Sigma, St. Louis, MO) dissolved in cold Stockholm's PBS, pH 7.3. Aggregates were then washed three times in $10 \mathrm{ml}$ of Stockholm's PBS and equilibrated in 30\% w/v sucrose (Sigma) at $4^{\circ} \mathrm{C}$. Samples were then embedded in cryoprotectant and sectioned on a Jencon's OTF5000 cryostat at $15 \mu \mathrm{m}$ thickness.

Chimeras. Cells were centrifuged at $1500 \mathrm{rpm}$ and resuspended in $\sim 1$ $\mathrm{ml}$ of serum-free media. Cells were dissociated mechanically into a single-cell suspension and counted on a hemacytometer. Cells were reconstituted at 5000-20,000 cells/ $\mu$ l for blastocyst injections or 50,000$100,000 \mathrm{cells} / \mu \mathrm{l}$ for ultrasound-guided injections. Morula aggregations (performed using $3 \mathrm{~d}$ colonies of cells) and blastocyst injections were performed as described previously (Nagy et al., 2002), using Institute of Cancer Research (ICR) host morula and ICR pseudopregnant recipients. E9.5 chimeras were performed essentially as described previously (Slevin et al., 2006), using high-frequency ultrasound microscope Veve-660 with $40 \mathrm{MHz}$ probe (VisualSonics, Toronto, Ontario, Canada). For each assay, 14-69 $\mathrm{nl}$ of serum-free media containing 1400-14,000 cells were injected directly into the telencephalic ventricle of E9.5 embryos. After each procedure, the embryos of one pregnant dam were killed and dissected to confirm the presence of injected cells in the telencephalon $1-2 \mathrm{~h}$ after injection. Because the brain is one continuous tube at this time 
point, random cell leakage throughout the forebrain and sometimes into midbrain and hindbrain regions was unavoidable.

Plasmid construction and retroviral infection. The pMXIE retroviral construct has been described previously (Hitoshi et al., 2002). To generate the pMXIE-E-cadherin construct, Human E-cadherin cDNA was amplified by PCR in a $50 \mu \mathrm{l}$ volume consisting of $1 \mu \mathrm{M}$ sense $\left(5^{\prime}\right.$ CCCTCGCTCGAGGTCCCCGGCCCAG- $\left.3^{\prime}\right)$ and antisense (5'CCTCTCTCGAGATCTCTAGTCGTCCTCG-3') primers, $2.5 \mathrm{~mm}$ $\mathrm{Mg}^{2+}, 0.3 \mathrm{~mm}$ deoxyribonucleotide triphosphate, $1 \mu \mathrm{l}$ of TaKaRa LA Taq polymerase (TaKaRa, Tokyo, Japan) and pLKpacl human Ecad plasmid (a gift from Dr. Reynolds, St. Jude Children's Hospital, Memphis, $\mathrm{TN}$ ) as a template. PCR parameters included denaturation at $95^{\circ} \mathrm{C}$ for $30 \mathrm{~s}$, annealing at $60^{\circ} \mathrm{C}$ for $60 \mathrm{~s}$, and extension at $72^{\circ} \mathrm{C}$ for $180 \mathrm{~s}$ for 20 cycles. The amplified DNA fragments were digested with XhoI and BglII and ligated to the XhoI-BamHI site of the pMXIE retroviral vector plasmid. One hundred thousand cells were exposed to virus at a ratio of 10 virus particles to one cell in the presence of $5 \mathrm{ng} / \mu \mathrm{l}$ hexadimethrine bromide (Sigma). Cells were incubated with retrovirus in $250 \mu \mathrm{l}$ of cell culture media (containing EGF and FGF) for 90 min while being centrifuged at $1000 \mathrm{rpm}$ at room temperature. Cells were then resuspended, recounted, and plated as described above. Before use, colonies were examined to confirm retrovirus integration and transgene expression by fluorescence microscopy. Only GFP $(+)$ colonies were picked for use in morula aggregations.

Quantitative PCR. Messenger RNA was extracted using the RNeasy Microkit (Qiagen, Valencia, CA). One microgram of RNA was converted to cDNA using oligo $\mathrm{dT}_{20}$ (Invitrogen, Carlsbad, CA) and Superscript III reverse transcriptase (Invitrogen). Real-time PCRs were run using SYBR Green (Applied Biosystems, Foster City, CA), and analyzed using the ABI Prism 7000 sequence detection system. Cadherin levels were determined using the comparative $\mathrm{C}_{\mathrm{T}}$ method with glyceraldehyde-3-phosphate dehydrogenase (GAPDH) as reference. Primer pairs sequences used were as follows: Cdh1, forward, TCATTTTGCAACCAAGAAAGGA; reverse, CCGCGAGCTTGAGATGGA; Cdh2, forward, TCTGTTCCAGAGGGATCAAAGC; reverse, TTGGATCATCCGCATCAATG; Cdh3, forward, GCCAGGACTCTGAAGTTTGC; reverse, CAAGTTCAAGCCCTGAGAGG; GAPDH, forward, CACACCGACCTTCACCATTTT; reverse, GAGACAGCCGCATCTTCTTGT.

Embryo and pup dissection. Embryos and pups were fixed using 2\% paraformaldehyde (Sigma) dissolved in cold Stockholm's PBS, pH 7.3. E10.5 embryos were fixed for $1 \mathrm{~h}$ at room temperature on a shaker. E12.5 embryos were fixed for $1 \mathrm{~h}$ on a shaker and then bisected sagittally and fixed for an additional $1 \mathrm{~h}$ at room temperature on a shaker. E13.5 embryos were decapitated, and their heads were fixed for $1 \mathrm{~h}$ on a shaker and then bisected sagittally and fixed for an additional $1 \mathrm{~h}$ at room temperature on a shaker. Postnatal day 1 (P1) pups were anesthetized with isoflurane gas and perfused with $2 \mathrm{ml}$ of Stockholm's PBS and $2 \mathrm{ml}$ of $2 \%$ paraformaldehyde. Brains were then dissected from cranium and further fixed in 2\% paraformaldehyde overnight. Embryos and pups were immersed in Stockholm's PBS containing 30\% w/v sucrose (Sigma) until equilibrated at $4^{\circ} \mathrm{C}$. A mixture of $30 \%$ sucrose and cryoprotectant (Thermo Electron Corporation, Pittsburgh, PA) was then applied for $24-48 \mathrm{~h}$ to each sample on a shaker at $4^{\circ} \mathrm{C}$. Samples were then embedded in cryoprotectant and sectioned on a Jencon's OTF5000 cryostat at 15 $\mu \mathrm{m}$ thickness.

Immunofluorescence and microscopy. Sections or embryos were washed 3 times for 10 min with Stockholm's PBS plus $0.3 \%$ Triton X-100 detergent (Sigma). Sections were then blocked using $1 \%$ bovine serum albumin (Sigma) plus 10\% normal goat serum (Sigma) in Stockholm's PBS, $\mathrm{pH} 7.3$, and $0.3 \%$ Triton X-100 (Sigma) for $60 \mathrm{~min}$ at room temperature. Primary antibodies were applied overnight in Stockholm's PBS, $1.0 \%$ NGS, and $0.3 \%$ Triton X-100. Anti-nestin (1:1000; Millipore, Billerica, MA), anti- $\beta$-tubulin isotype III (1:500; Sigma), anti-HNF3- $\beta$ (1:100; clone 4C7; Developmental Studies Hybridoma Bank, University of Iowa, Iowa City, IA), anti-Brachyury (1:200; Santa Cruz Biotechnology, Santa Cruz, CA), and anti-glial fibrillary acidic protein (GFAP; 1:400; Sigma) were used. Sections were washed three times in Stockholm's PBS and blocked again using the same conditions above. Secondary antibodies were applied at $37^{\circ} \mathrm{C}$ for $2 \mathrm{~h}$ in StPBS $1.0 \%$ normal goat serum. Goat anti-mouse or goat anti-rabbit $568 \mathrm{~nm}$ Alexa Fluor antibodies (1:300; Invitrogen) were used as appropriate. Nuclei were counterstained with $10 \mu \mathrm{g} / \mathrm{ml}$ Hoechst 33258 (Sigma). Cells were photographed in Stockholm's PBS or serum-free media, embryos were photographed in Dulbecco's PBS, and sections were mounted and coverslipped using Gel Mount (Biomeda, Foster City, CA). Embryo photographs were taken under a $1 \times / 0.75$ (dry lens) objective using a MZFLIII Leica (Bannockburn, IL) microscope with a Nikon (Tokyo, Japan) CoolPI 3.34 megapixel digital camera mount. Section photographs were taken under $40 \times / 0.55$ (dry lens) objective using a $40 \times / 0.60$ Olympus (Tokyo, Japan) IX81 inverted microscope with the Olympus Microsuite Version 3.2 Analysis imaging system software (Soft Imaging System, Münster, Germany). Confocal photography was undertaken with a Leica TCS2 confocal microscope with Leica HC PL APO $20 \times / 0.70$ objective; pinhole at Airy unit 1 ; with confocal sections taken approximately every $5 \mu \mathrm{m}$. All photos were processed using Adobe (San Jose, CA) Photoshop 6.0 software.

Fluorescence-activated cell sorting. Cells were sorted on fluorescenceactivated cell sorting (FACS) DiVa (BD Biosciences, San Jose, CA) system. Cells were sorted at $\sim 9000$ events/s, and fractions were kept on ice until plated. At the outset of each experiment, CD1 (GFP-negative) adult neurosphere cells and GFP transgenic adult neurosphere cells served as negative and positive controls, respectively, to set the gates for cell sorting. Collected cells were allowed $1 \mathrm{~d}$ to recover from sorting, at normal growth conditions. Fluorescence microscopy confirmed the positivity of retrovirus-infected cells just before use. To confirm E-cadherin presence, retrovirus-infected cells were dissociated mechanically and blocked for $30 \mathrm{~min}$ at $37^{\circ} \mathrm{C}$, in Dulbecco's PBS, pH 7.3, plus $10 \%$ normal goat serum (Sigma). Cells were then exposed to $2 \mu \mathrm{g} / \mathrm{ml}$ primary anti-E-cadherin antibody ECCD2 (1:500; Zymed, San Francisco, CA), in $1 \mathrm{ml}$ of Dulbec-

\section{Table 1. Cell-sorting assay}

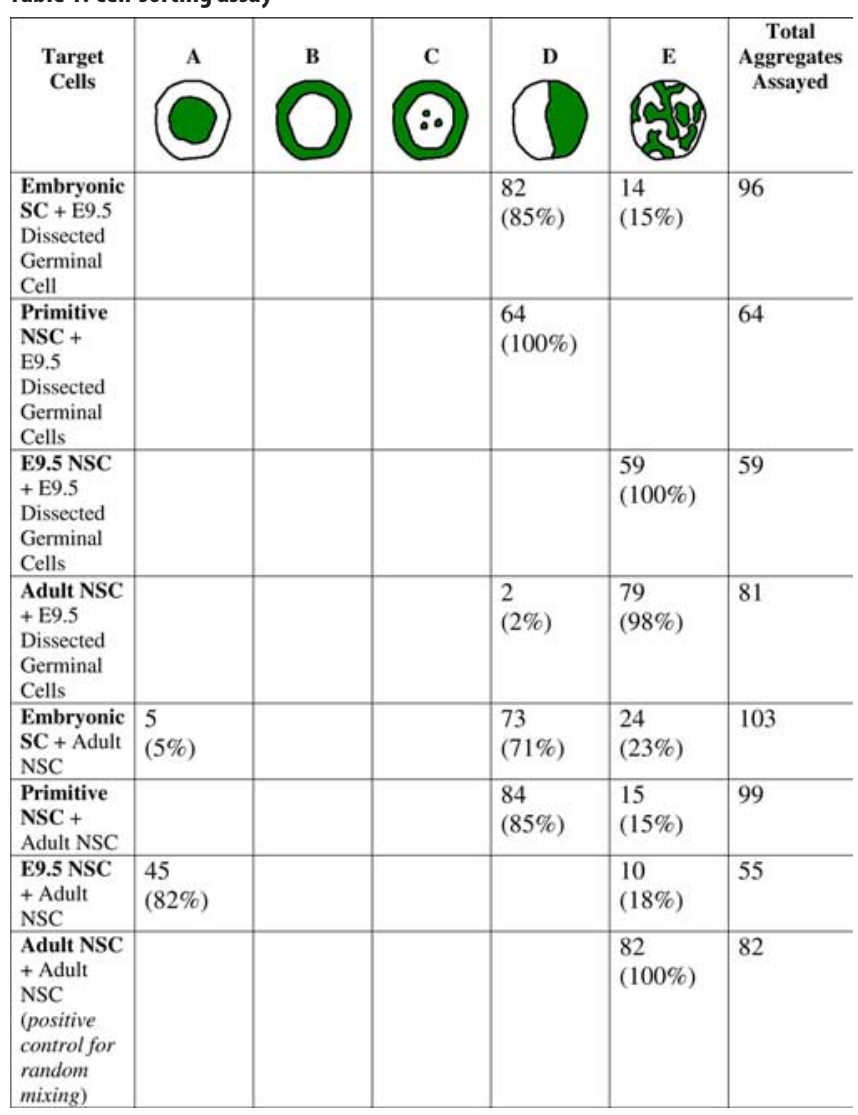

Labeled target cells were mixed with unlabeled cells in equal portions. Cellular aggregates were examined after overnight incubation and scored into categories as depicted in the table. A, Target cells within host cells, a spherewithin-sphere configuration; B, target cells completely outside host cells, a reverse sphere-within-sphere configuration; $C$, most target cells peripheral to host cells but some target cells within central regions; D, complete sorting out, in which target and host cells possess little adherence; E, random sorting process, a complete mottling of target and host cells. Parentheses indicate percentages of aggregates scored in these categories. 
co's PBS plus $3 \%$ goat serum for $1 \mathrm{~h}$ at $37^{\circ} \mathrm{C}$. Cells were then washed twice in $10 \mathrm{ml}$ of Dulbecco's PBS and exposed to goat anti-mouse $633 \mathrm{~nm}$ Alexa Fluor antibody (1:300; Invitrogen) for an additional $1 \mathrm{~h}$ in the same conditions as the primary. Cells were then washed twice in $10 \mathrm{ml}$ of Dulbecco's PBS and sorted. ESCs served as positive controls to confirm the efficacy of the E-cadherin antibody.

\section{Results}

In vitro cell-sorting assays reveal adhesive differences between SCs Cell-to-cell adherence can be directly compared by coculturing two types of cells at high density overnight (Foty and Steinberg, 2005). Although initially randomly assorted in aggregates, each cell type will sort in a way that minimizes free adhesive surface proteins and maximizes the strongest protein-to-protein contacts. Additionally, cells with very weak affinity might completely sort away from one another if adhesive forces holding them together are insufficient. Aggregates examined using this method were scored according to the qualitative categories shown (Table 1).

We cocultured ESCs, primitive NSCs, E9.5-derived definitive NSCs, and adult definitive NSCs in pairs with each other and with cells dissected from the E9.5 telencephalic germinal zone. In each case, one group of cells was $\operatorname{eYFP}(+)$, and the other was unlabeled. With the exception of ESCs, these cell types were dissociated manually and not through the use of enzymes, which might digest external adhesive proteins. Thus, cells would retain their autochthonous component of extrinsic adhesion proteins, which enzymes have been noted to alter (Olsson et al., 1998). We reasoned that such cocultures would establish predictions as to the behavior of cells transplanted into the early mouse morula and the E9.5 telencephalon, the embryonic stages in which the differentiation capacity of such cells would be tested. All aggregates were initially observed as randomly sorted, and the following phenomena were observed only after overnight incubation. ESCs or primitive NSCs sorted away from E9.5 germinal zone cells in aggregates, in contrast to E9.5-derived or adultderived NSCs, which sorted randomly with E9.5 germinal zone cells in aggregates (Fig. $2 A-C$ ). As well, ESCs or primitive NSCs sorted away from adult NSCs, with primitive NSCs possessing nearly no adherence to the adult cells. This suggests that the early embryonic SCs have little affinity for the later embryonic and adult SCs nor for E9.5 telencephalic cells present in the later stages of neural development. E9.5-derived NSCs sorted into the center of aggregates when cocultured with adult NSCs (Fig. $2 A, C)$, suggesting that the adhesion between the E9.5 NSCs themselves was stronger than that between the adult NSCs themselves (Fig. 2 B) or between the E9.5 and adult NSCs. In some ii.

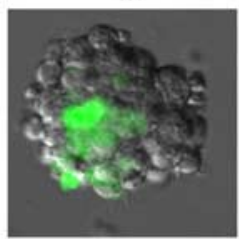

Adult NSC +

E9.5-Derived

Definitive NSC iii.

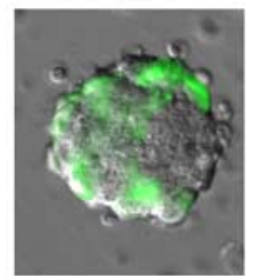

E9.5 Germinal

Zone Cells +

Adult Definitive NSC iv.

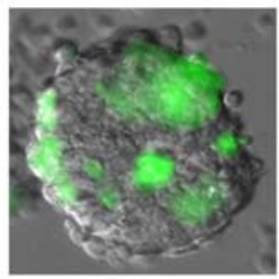

E9.5 Germinal

Zone Cells +

E9.5-Derived

Definitive NSC
B.
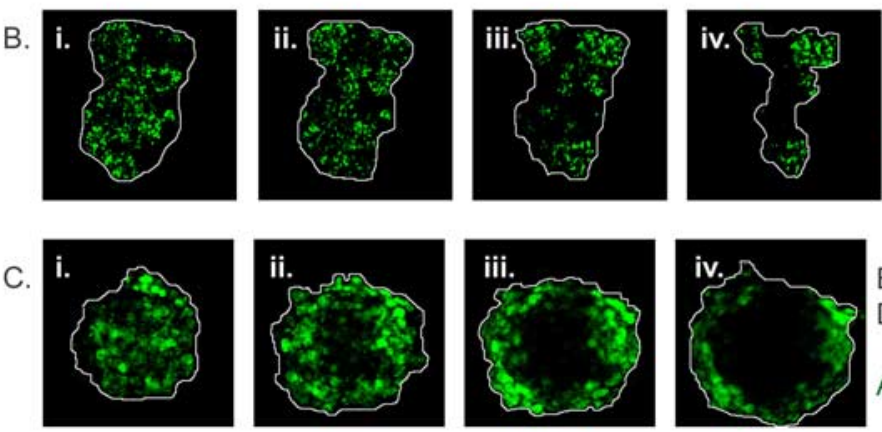

E.

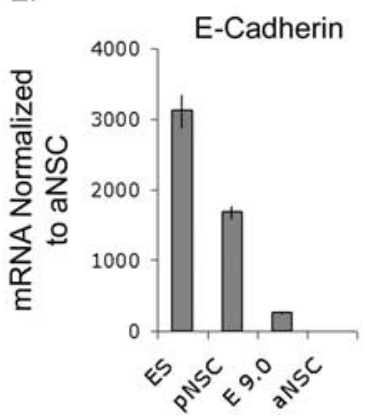

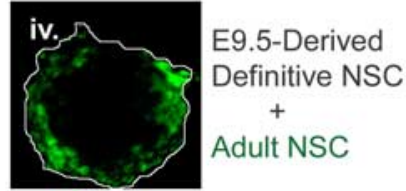

F.
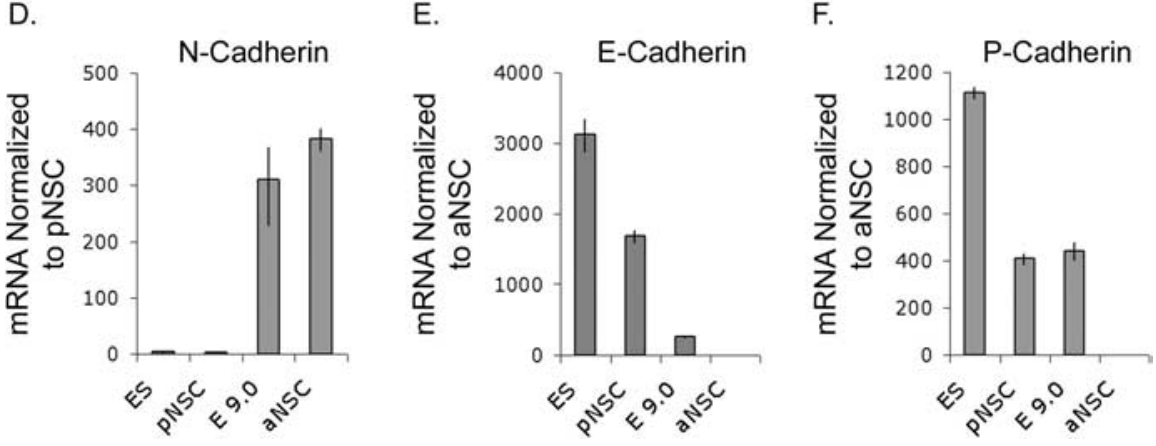

Figure $2 \boldsymbol{A}$, Cellular aggregates. Overnight, target and host cells sorted into distinct regions of aggregates: $\boldsymbol{i}$, Experiments mixing unlabeled E9.5 germinal zone cells with primitive NSCs (green); in this case, both populations of cells are sorted apart. ii, When E9.5-derived NSCs (green) are mixed with unlabeled adult NSCs, the more adhesive E9.5-derived cells sort into the center of aggregates. iii, iv, Mixing of both E9.5- and adult-derived NSCs (green), respectively, with unlabeled E9.5 germinal zone cells is random. $\boldsymbol{B}$, Random aggregates. $\boldsymbol{i}-\boldsymbol{i} \boldsymbol{v}$, Four serial confocal sections taken at $10 \mu \mathrm{m}$ intervals. These show that two adult-derived NSC populations, one nonfluorescent and one YFP(+) (green), sort randomly. Aggregate is outlined in white. C, Sphere-withinThe graph shows the amount of N-cadherin mRNA expressed by ESCs, primitive NSCs (pNSC), E9.0-derived NSCs (E9.0), and erived NSCs, and adult-derived NSCs. In this case, levels are normalized to adult NSCS, the lowest-expressing group. $\boldsymbol{F}$, Relative P-cadherin transcript abundance. The graph shows the amount of P-cadherin mRNA expressed by ESCs, primitive NSCs, E9.0derived NSCs, and adult-derived NSCs. In this case, levels are normalized to adult NSCs, the lowest-expressing group.

cases, we found that adult NSCs also sorted to the periphery of aggregates when cocultured with ESCs, suggesting a similar interaction. These results were consistent in a large population of aggregates examined and are shown summarized in Table 1.

We predicted that these cell-sorting behaviors resulted from different expression of cadherins in cells in the NSC lineage. To test this, samples were tested for relative cadherin transcript abundance by quantitative PCR. We found that E9.0- and adultderived neurosphere cells expressed $\mathrm{N}$-cadherins at over two orders of magnitude higher amounts than ESCs and primitive NSCs (Fig. 2D). In contrast, E-cadherin was expressed by ESCs and primitive NSCs $>100$ times higher than in E9.0- and adult- 
i.

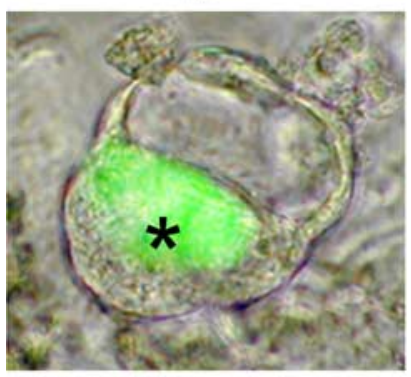

Primitive NSC ii.

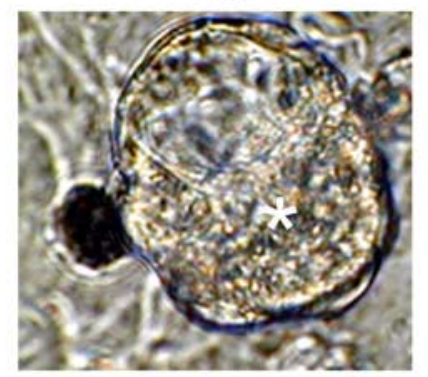

Adult Retinal SC iii.

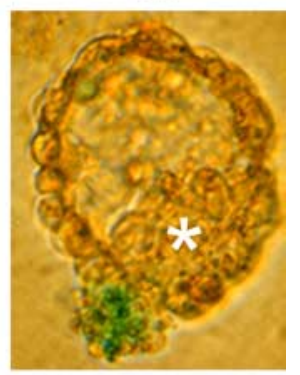

Adult Definitive NSC

Figure 3. Morula aggregates discriminate between adherent and nonadherent cells. $i$, Early ESC-derived primitive NSC (green) are competent to colonize the ICM, because they adhere to these cells, after overnight incubation, as shown in merge of bright field and fluorescence. $\mathbf{i i}$, iii, Bright-field photographs show that pigmented adult retinal SCs (dark; ii) and LacZ(+) adult NSCs (blue; iii) are not competent to colonize the ICM. Both colonies remain outside of host embryo. Either LacZ or fluorescent protein markers were used in these experiments. Asterisks indicate position of ICM.

derived neurosphere cells (Fig. 2 E). These data correlate with the inability of ESCs and primitive NSCs to intermingle with adult cells and those derived from the midgestation (E9.5) embryo. Moreover, E9.0 neurosphere cells express 400 times higher levels of P-cadherin than adult neurosphere cells (Fig. $2 F$ ), which could account for the observation that the E9.5 cells sort within the center of E9.5 NSC/adult NSC cocultures. Although these cells possess similar $\mathrm{N}$-cadherin levels, the additional $\mathrm{P}$-cadherin adhesion presumably results in tighter association of E9.5 cells to each other than to the adult cells, driving these into central regions of the aggregates.

We infected adult NSCs with an E-cadherin/GFP-expressing construct and collected GFP $(+)$ cells by FACS $7 \mathrm{~d}$ after infection. We confirmed that $78.1 \pm 2.3 \%$ of $\mathrm{GFP}(+)$ cells reacted positively with E-cadherin antibodies. Forcible overexpression of E-cadherin protein (which is present in ESCs) was sufficient to alter the cell sorting observed in cocultures of adult NSCs and ESCs when these were cultured as embryoid bodies for $7 \mathrm{~d}$ in vitro. Control retrovirus overexpressing adult NSCs sorted in the center in only 6 of 32 of the embryoid bodies observed. In contrast, 49 of 56 E-cadherin-overexpressing adult NSC/ESC embryoid bodies demonstrated increased localization of adult-derived cells with ESC-derived cells in the center of aggregates. Of these, $\sim 35.2 \pm 5.0 \%$ of E-cadherin $(+)$ adult NSC progeny were near the center of $7 \mathrm{~d}$ embryoid body sections examined ( $n=19$ E-cadherin-overexpressing adult NSC/ESC aggregates sampled).

Thus, our data suggest that cellular adhesion between cells of the NSC lineage varies considerably during development but that such discrepancies can be experimentally modulated.

Adult NSCs and retinal SCs do not adhere to the early embryo The morula aggregation technique involves the juxtaposition of SC colonies with the four- to eight-cell-stage mouse embryos, the ICM, adult NSC colonies in no case were successfully integrated into the ICM (Fig. 3). We also attempted the aggregation of adult retinal SC colonies, but like adult NSCs, these did not sort with the embryo (Fig. 3). These results, shown summarized in Table 2, might explain the rare-tononexistent recruitment of adult SCs in early embryos (Clarke et al., 2000; Tropepe et al., 2001; D'Amour and Gage, 2003; Greco et al., 2004). Even if such adult NSCs possess generalized pluripotency, the inability of such cells to associate with the ICM results in the failure of these cells to contribute prima facie. The few instances in which cells remained associated with the trophoblast cells that surround the blastocyst (Table 2) indicate that rare association of adult cells in the early embryo is possible.

\section{Adult NSCs, induced to adhere to the early embryo, cannot produce non-neural cell types}

Because our data indicated that adult NSCs could be induced to intermingle in vitro with ESCs by E-cadherin overexpression as described above, we attempted to introduce E-cadherinoverexpressing adult NSCs into the ICM by morula aggregation. E-cadherin-overexpressing adult NSCs showed a modest increase in associating with the ICM and trophoblast of the embryo (Table 2). The residual presence of $\mathrm{N}$-cadherin in the adult cells might explain why these failed in most cases to aggregate with the early embryo, even when E-cadherin was overexpressed. The few embryos that contained adult NSCs did not result in the detectable contribution of such cells in any part of the developing conceptus, when these embryos were reimplanted after aggregation.

We next attempted to introduce adult cells by injection into the blastocoel cavity of the blastocyst, in an attempt to improve the access of the adult NSCs. Unlike previous studies (Clarke et al., 2000; D'Amour and Gage, 2003; Greco et al., 2004), we examined blastocysts for the presence of introduced cells $12-16 \mathrm{~h}$ after

Table 2. Morula aggregations

\begin{tabular}{|c|c|c|c|c|c|}
\hline & $\begin{array}{l}\text { Total number } \\
\text { of embryos }\end{array}$ & $\begin{array}{l}\text { Aggregated cells in or } \\
\text { next to ICM (number) }\end{array}$ & $\begin{array}{l}\text { Aggregated cells in } \\
\text { trophoblast (number) }\end{array}$ & $\begin{array}{l}\text { Aggregated cells in } \\
\text { or next to ICM (\%) }\end{array}$ & $\begin{array}{l}\text { Aggregated cells in } \\
\text { trophoblast (\%) }\end{array}$ \\
\hline Adult retinal NSCs & 357 & 0 & 0 & 0 & 0 \\
\hline Adult forebrain NSCs & 496 & 0 & 31 & 0 & 6.3 \\
\hline E-cadherin-overexpressing adult forebrain NSCs & 229 & 7 & 34 & 3.1 & 14.8 \\
\hline Primitive NSCs & 75 & 65 & 0 & 86.5 & 0 \\
\hline
\end{tabular}

Morula aggregates of adult NSC colonies fail in contrast to early NSCs. Examination of morula aggregation after overnight incubation reveals that unlike primitive NSCs, adult definitive NSCs and retinal SCs cannot adhere to early embryonic cells. Introduction of such cells into the blastocyst is predicted to fail, prima facie, because such cells do not persist in a nonadherent environment. Overexpression of E-cadherin in adult definitive NSC colonies allows a small percentage of these to sort into the ICM, in contrast to wild-type adult NSC colonies. Note the increase in both ICM and trophoblast association by the introduced cells. 
blastocoel injection and before reimplantation (Fig. 4A). Significantly, E-cadherin/ GFP-expressing adult NSCs associated with the blastocyst ICM in $\sim 37 \%$ of the cases, in contrast to control adult NSCs (GFP only), which only associated with the blastocyst $\sim 3 \%$ of the time (Table 3 ). Again, that the E-cadherin-overexpressing adult NSCs maintained their constitutive expression of $\mathrm{N}$-cadherin explains why this frequency is not higher. The exact location of the adult cells was confirmed by confocal microscopy with some of the adult cells in the ICM (Fig. $4 \mathrm{Ai}$ ), apposed to the ICM (Fig. 4Aii), or in the blastocoel cavity but not near the ICM (Fig. 4Aiii). Interestingly, in 22 of 73 instances $(\sim 30 \%)$, the control adult NSCs were expelled from the blastocyst overnight similar to the morula aggregations, with the majority either remaining unattached to the ICM in the blastocoel cavity or dying overnight (Fig. 3). We implanted all blastocysts containing adult NSC progeny and examined the embryos at E4.5 and E6.5. Control adult NSC injected blastocysts showed no presence of the transplanted cells at E4.5 and E6.5. Similarly, at E4.5, E-cadherin-overexpressing adult NSCs were no longer present in the developing embryo, but we were able to visualize adult cells in the extraembryonic tissues of 4 of 34 embryos recovered at E4.5 (data not shown). Despite the increased frequency of association between E-cadherin-overexpressing adult NSCs and that of normal adult NSCs, the contribution of these adult NSCs was not like that of ESCs, which associated with the ICM and which persisted up to E6.5 in all cases examined (Table 3 ).

The E-cadherin-overexpressing adult NSCs, after blastocoel injection and overnight association with the ICM, were examined by marker analysis. Blastocysts were stained for the proteins nestin and GFAP, believed to correspond to neural cell types. All transplanted adult NSC progeny in the blastocyst were positive for nestin (Fig. $4 B$ ), and three of nine transplanted cells were positive for GFAP after overnight incubation (data not shown).

\section{Adult NSC potency is restricted in embryoid body coculture}

The pluripotency of ESCs can be assessed via the in vitro differentiation of embryoid bodies. Marker-based characterization of germ layer progenitors, using genes such as Brachyury (Kubo et al., 2004) for mesodermal progenitors, can be used in such assays to characterize the differentiated cell output of ESCs. Because adult NSCs
A.
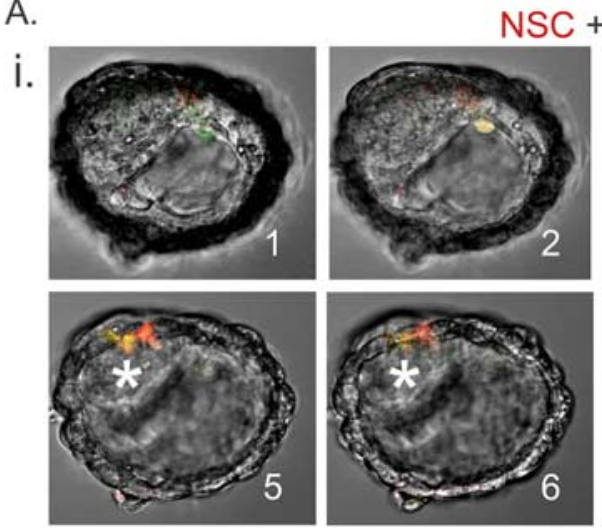

ii.

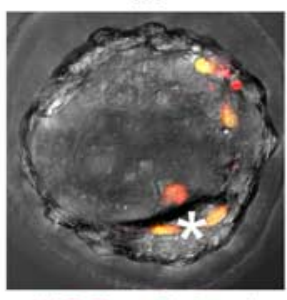

$\mathrm{NSC}+\mathrm{E}-\mathrm{Cad}$

B.
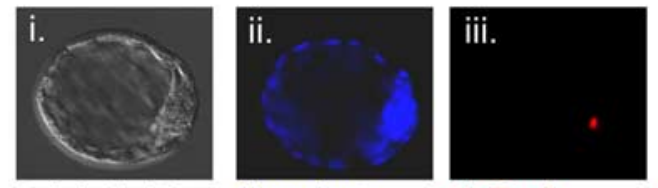

Brightfield

Hoechst

dsRed
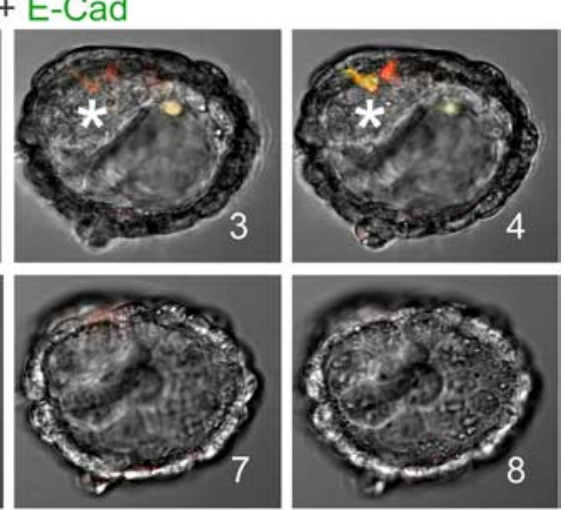

iii.

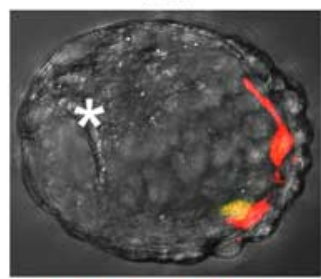

$\mathrm{NSC}+\mathrm{E}-\mathrm{Cad}$

C.
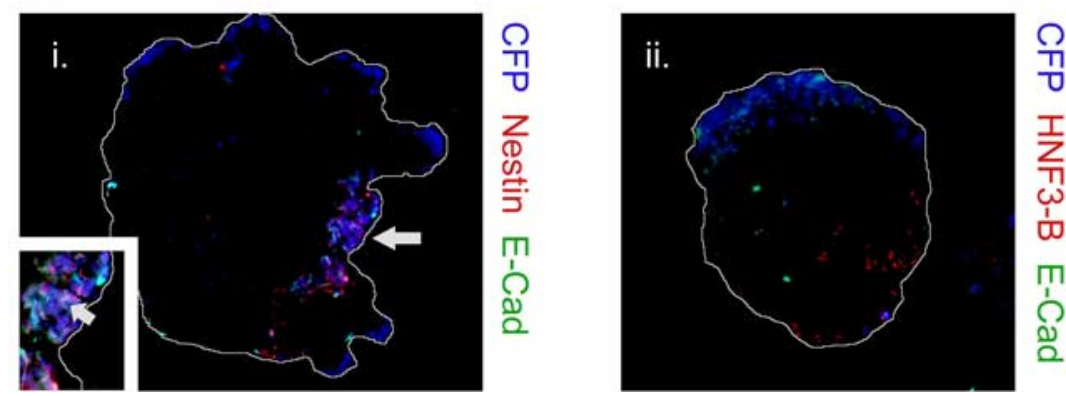

Figure $4 \quad \boldsymbol{A}$, E-cadherin-overexpressing adult definitive NSCs persist in the blastocyst. $\boldsymbol{i}$-iii, After injection of cells into E3.5 blastocysts, adult dsRed-MST (red)/E-cadherin-overexpressing (green) cells are inside ICM (i), apposed to ICM (ii), or inside blastocoel cavity but not associated with ICM (iii). $i 1-i 8$, Sequential confocal slices demonstrating the presence of introduced cells in relation to ICM (asterisks). ii, iii, Merged confocal $z$-stacks. Variability in E-cadherin levels, evidenced by GFP expression (green), is likely a result of variability in the insertion sites of the retroviral cassette. In some cases, the blastocysts expanded overnight, enlarging blastocoel cavity greatly (compare $\boldsymbol{i}$, ii). $\boldsymbol{B}$, Adult NSCs retain neural markers in blastocyst chimeras. All adult cells remained nestin positive after blastocyst injection and overnight incubation in $n=6$ embryos examined. Embryos were also stained for GFAP, and three of nine adult dsRed-MST(+) cells showed weak GFAP positivity in $n=3$ embryos. This suggests that most adult cells remained neural and were not dedifferentiated nor transdifferentiated after blastocyst injection. $\boldsymbol{i}$, Bright field. $\boldsymbol{i i i}_{\text {, }}$ Blastocyst nuclei counterstained with Hoechst (blue). iii, Adult dsRed(+) NSC progeny (red). iv, Nestin (green). $\boldsymbol{v}$, Merge of iii and iv. After fixation, GFP fluorescence emitted from E-cadherin retroviral gene expression was quenched, allowing for the examination of these proteins by immunohistochemistry. C, Differentiation of adult-derived NSC progeny in association with ESC progeny is insufficient to alter potency. We cocultured E-cadherin-overexpressing (green) adult NSC progeny with ESCs in embryoid bodies for $7 \mathrm{~d}$. During this time, most E-cadherin transgene expression was shut off by the differentiating NSC progeny. $\boldsymbol{i}$, Sections revealed that adult CFP( + ) NSC descendants (blue) were nestin positive (red). Inset, A close-up demonstrating colocalization of nestin and adult NSC-derived cells. ii, Sections showed that in no case were adult NSC descendants (blue) positive for HNF3- $\beta$ (red). Arrow indicates positively marked adult NSC progeny. Embryoid bodies are outlined for clarity. E-Cad, E-cadherin. 


\begin{tabular}{|c|c|c|c|}
\hline & Associated with ICM at E3.5 (\%) & Associated with epiblast at E4.5 (\%) & Associated with epiblast at E6.5 (\%) \\
\hline Adult forebrain NSCs (control retrovirus) & $2.60(n=77)$ & $0(n=9)$ & $0(n=9)$ \\
\hline Adult forebrain NSCs with E-cadherin overexpression & $36.98(n=204)$ & $0(n=34)$ & $0(n=19)$ \\
\hline Embryonic stem cells & $100.00(n=90)$ & Not determined & $100.00(n=20)$ \\
\hline
\end{tabular}

Increased association of adult-derived NSCs after E-cadherin overexpression and blastocoel injection. Ratios showing association of blastocyst-injected cells with ICM after overnight incubation. Control cells only persisted in the ICM < $3 \%$ of the time. Indeed, in $\sim 30 \%$ of adult NSC colonies, cells were expelled from the embryo overnight, with the remainder persisting in the blastocoel cavity, in which they cannot contribute to the epiblast. E-cadherin-overexpressing adult NSCs associated with the ICM in $\sim 37 \%$ of these cases, a substantial increase. However, ESCs integrated with the ICM in all cases examined. Number of samples examined is indicated in parentheses.

sort away from ESCs in in vitro coculture, we examined the potency of adult NSCs by the forcible association of these cells with differentiating ESCs in embryoid bodies. Association of adult NSCs with non-neural cells has been reported to transmogrify neural cells into non-neural cell types (Wurmser et al., 2004). We similarly assessed adult NSC plasticity in embryoid bodies by mixing equal numbers of marked adult NSCs, infected with a GFP/E-cadherin retrovirus, and unlabeled ESCs. We investigated these aggregates for the presence of neural (Fig. 4Ci) and early non-neural markers (Fig. 4Cii). We used the markers nestin for neuroectodermal cells ( $n=7$ aggregates), Brachyury for mesodermal cells ( $n=8$ aggregates), and HNF3- $\beta$ for endodermal cells ( $n=6$ aggregates). The marker GFAP was chosen to assess differentiated NSC progeny ( $n=5$ aggregates). Sections of embryoid bodies grown up to day 7 in the presence of high serum were sampled to determine the ratio of marker-positive cells to total cells in the population. The adult-derived NSCs produced $33.1 \pm 4.9 \%$ nestin $(+)$ and $26.7 \pm 10.4 \%$ GFAP-positive progeny, yet they produced zero HNF3- $\beta$ or Brachyury progeny. Despite close association of E-cadherin-overexpressing adult NSC progeny with differentiating ESC progeny, NSC progeny expressed only neural cell markers in all $7 \mathrm{~d}$ embryoid body sections examined. We then assessed differentiation in $4 \mathrm{~d}$ embryoid body cocultures but found no appreciable differences to those at day 7 (data not shown). This experiment suggests that proximity does not induce pluripotency in these in vitro conditions.

\section{Adherence is necessary for stem cell recruitment}

The early embryonic brain was assayed next as a host to characterize potency differences between cells of the NSC lineage. We used the method of ultrasound-guided injection (Olsson et al., 1997) to inject cells into the E9.5 telencephalic ventricle to assess their potency therein. Labeled cells (1400-7000) were introduced into the E9.5 forebrain (Fig. 5A), and the animals were examined at several time points afterward. We assessed the relative contribution of cells in the NSC lineage: primitive NSCs, E9.5-derived definitive FGF-dependent NSCs, and adult-derived definitive FGF- as well as adult-derived definitive FGF plus EGF-dependent NSCs. At E10.5, $24 \mathrm{~h}$ after injection, cells descended from primitive NSCs appeared scattered as single cells or doublets within the ventricle of the brain (Fig. 5B). At E12.5, clusters of injected cells were apparent within or near mantle regions of the brain. Such clusters were randomly scattered through the forebrain and midbrain regions, as the introduced cells had access to midbrain areas via the ventricular cavity at the E9.5 time point. It was observed that cells derived from primitive NSCs had moved through the ventricle and passed through germinal regions and into presumptive mantle regions of the E12.5 embryo (Fig. $5 C$ ). By E13.5, primitive NSC colonies had been completely expelled from the brain and clustered as large ectodermal rosettes sandwiched between mantle regions and the ectoderm (Fig. 5D). It is surprising that large clumps of cells could move so readily through a mass of early neural tissue; however, it is possible that the cells move before proliferation, such that single cells or small clusters begin to proliferate into larger rosettes only after they reach their final position outside of the brain. Similar to the inability of adult NSCs to adhere to the early mouse embryo, primitive NSCs cannot adhere to the midgestation embryonic brain because of differences in cadherin expression (Fig. 2D,E). However, primitive NSCs are competent to give rise to neural cells, both when differentiated in vitro and when introduced into the blastocyst $6 \mathrm{~d}$ earlier in embryogenesis (Tropepe et al., 2001).

The E9.5- and adult-derived NSC progeny (data not shown) also were present in the ventricle at E10.5, as small clumps or single cells. At E12.5, clusters of adult or E9.5 definitive NSC descendants were associated with both germinal zones proximal to the ventricle as well as mantle regions. The E9.5-derived and adult-derived definitive NSCs introduced into the E9.5 embryo were not sorted out of the brain and were detected in brains recovered at P1. E9.5-derived NSC progeny were visible in whole mounts of P1 brains (Fig. 6A), as were adult-derived NSC progeny (Fig. $6 B$ ), and after closer inspection, cells of both descents possessed differentiated morphology. Because the E9.5-derived NSCs were grown in FGF alone, whereas the adult-derived NSCs were grown in both FGF and EGF, we repeated the adult-derived NSC ultrasound injections using adult-derived cells that were grown in FGF alone. We found no differences in contribution between adult-derived NSCs grown in FGF alone and those grown in EGF plus FGF (data not shown).

We characterized transplanted cells using the neural progenitor marker nestin, as well as $\beta$-3-tubulin, a marker of late neuronal progenitors and early neurons, and microtubule-associated protein 2 (MAP2), a marker of neurons. We found that in brains examined at $\mathrm{P} 1, \sim 12 \mathrm{~d}$ after transplantation, both $\mathrm{E} 9.5$ definitive NSCs (Fig. 7A) and adult definitive NSCs (Fig. $7 B$ ) gave rise to populations of nestin $(+), \beta-3(+)$, and MAP2 $(+)$ descendants, which possessed obvious differentiated morphology. Sections of primitive NSC colonies that had sorted outside of the E13.5 brain also possessed nestin- and $\beta$-3-positive progeny (Fig. $7 C$ ), but these did not possess any obvious differentiated morphology, and the proportion of MAP2 $(+)$ cells was much lower. Nonetheless, quantification of cell populations in sections sampled revealed that all three NSC cell lineages produced nestin-, $\beta$-3-tubulin-, and MAP2-marked cells (Fig. 7A-C). These data show that although all three cohorts derived from the NSC lineage possess the potency to generate neural and neuronal progeny, only the adultand E9.5-derived cells, which express appropriate levels of $\mathrm{N}$-cadherin, are competent to contribute to the developing brain when injected into the E9.5 telencephalon.

Our data suggest that after the E9.5 time point, definitive NSC progeny were not sorted out of neural tissues, in contrast to primitive NSC progeny (Table 4). Although both E9.5- and adultderived cells seemed able to persist in the P1 brain, the E9.5 cells appeared to persist more readily as viewed by whole mount ( $\mathrm{Ta}$ ble 4). Unlike the primitive NSCs, the adult- and E9.5-derived definitive NSC progeny did not produce any rosettes.

These results are consistent with the in vitro cell-sorting data described earlier, in which both adult and E9.5 cells sorted ran- 
domly among E9.5 telencephalic cells, which, in turn, sorted apart from the primitive NSCs. Indeed, the sorting of E9.5 cells into the center, when these are cocultured with adult cells, also represents an adhesive characteristic that might explain the relative increased contribution of E9.5 donor cells after transplantation into the E9.5 brain, compared with adult donor cells. Adhesion differences as assayed by relative cadherin transcript expression (Fig. 2B-D) (and not potency differences between definitive NSC progeny or primitive NSC progeny and the cells of the embryonic brain) underlie these contribution discrepancies.

\section{Discussion}

E-cadherin is the earliest expressed cadherin in the mouse embryo and is responsible for blastomere compaction as well as being involved in the earliest morphogenic events in mammalian embryogenesis (Larue et al., 1994; Neganova et al., 2000). After these events, cells within the developing neural tube downregulate E-cadherin to give way for the expression of $\mathrm{N}$-cadherin as well as other cadherins and integrins, which will compartmentalize the various regions of the nervous system (Shimamura and Takeichi, 1992; Redies, 2000). This evolving regulation of cadherins partially explains the eventual separation of cells in different tissues, which are spawned from a common source during development.

Cell-sorting assays and quantitative PCR reveal that substantial adhesion discrepancies exist between ESCs and their descendants, cells of the NSC lineage, although in vitro NSCs are distinguishable only by their requirements for different exogenous growth factors (Tropepe et al., 1999, 2001). Together our data suggest the following: (1) Primitive NSC progeny and ESCs possess different adhesion molecules from E9.5 germinal zone cells, adult NSC progeny, or E9.5 NSC progeny. (2) ESCs and primitive NSC progeny possess adhesion molecules compatible with the early mouse morula. (3) E9.5 NSCs and their descendants, as well as adult NSCs and their descendants, intermingle randomly with E9.5 germinal zone cells. These definitive NSC populations possess cell-cell adhesion molecules compatible with E9.5 germinal zone cells. (4) Despite this compatibility with germinal zone cells, the E9.5- and adult-derived NSC progeny show adherence differences. E9.5 cells sort into the center of aggregates undertaken between E9.5- and adult-derived NSC descendants. Thus, the adhesion of E9.5 NSC progeny to one another is stronger than the adhesion of adult NSC progeny to one another, as well as that of adult NSC progeny to E9.5 NSC progeny.

B.

C.
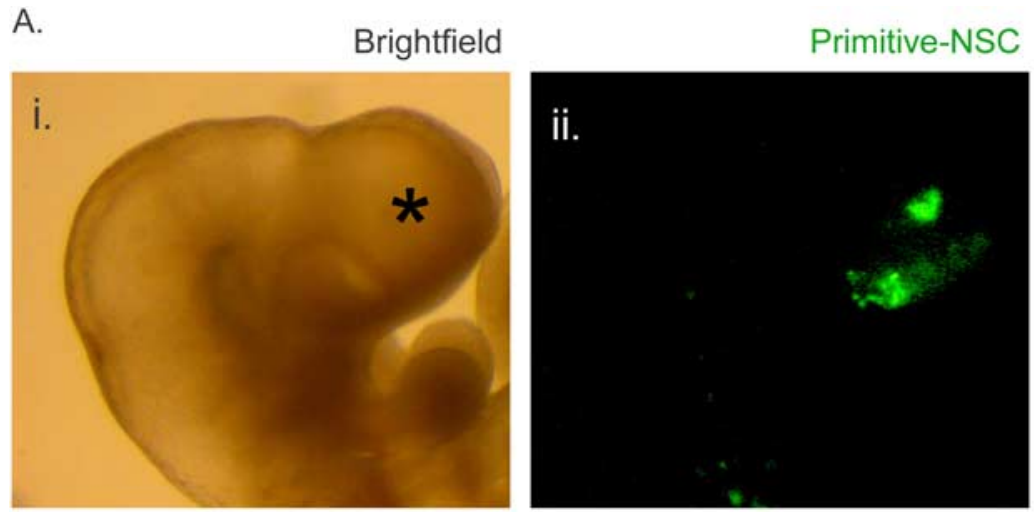

Brightfield
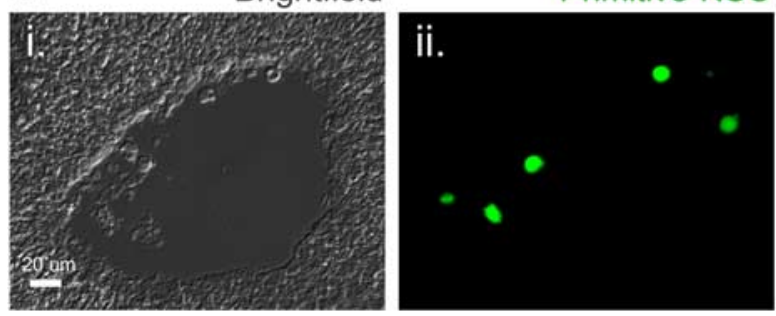

Primitive-NSC

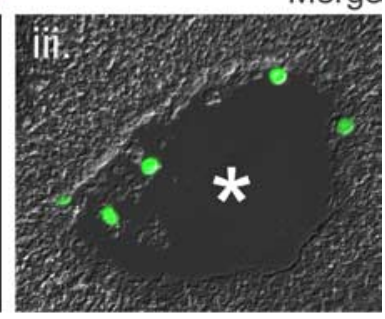
Brightfield

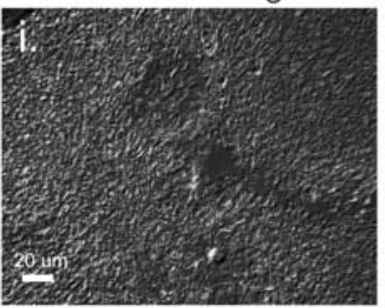

Primitive-NSC
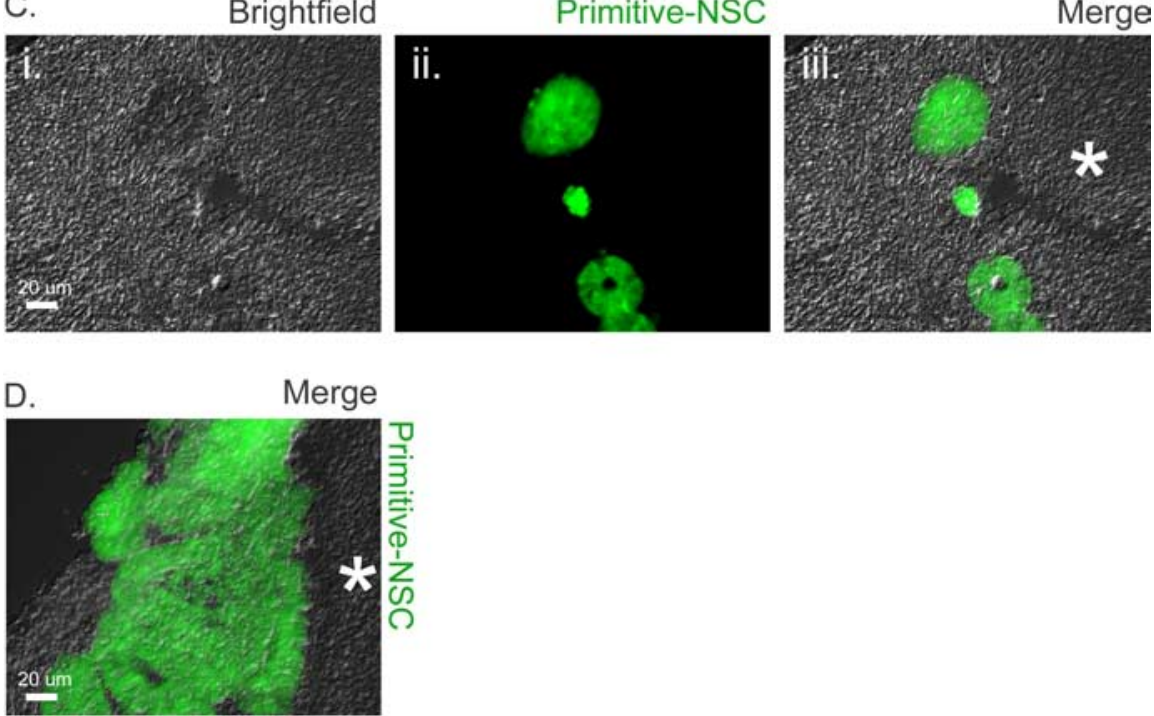

Figure $5 \quad \boldsymbol{A}$, Visualization of cells transplanted into E9.5 brain. Depicted are 1400 labeled primitive NSC progeny (green) as seen in whole mount of the E9.5 forebrain (indicated by asterisk) $1 \mathrm{~h}$ after ultrasound-guided injection. The presence of all other cell types assayed was similarly confirmed, in a subset of embryos, immediately after injection. $i$, Bright field of whole mount. $i \boldsymbol{i}$, $\mathrm{GFP}(+)$ transplanted cells in same embryo. $\boldsymbol{B}$, Transplanted cells persist in the forebrain at $24 \mathrm{~h}$ after injection. Single primitive NSCs (green) were seen within or attached to the walls of the telencephalic ventricle $24 \mathrm{~h}$ after transplant. $i$, Bright field of E10.5 brain section. ii, GFP(+) transplanted cells. iii, Merge. Asterisk indicates ventricle. $\boldsymbol{C}$, Transplanted cells form colonies in the developing brain. Seventy-two hours after transplant, colonies or rosettes of cells descended from primitive NSCs were observed in or near the presumptive mantle regions of the forebrain. $\boldsymbol{i}$, Bright field of E12.5 brain section. $\mathbf{i i}, \mathrm{GFP}(+)$ transplanted cells. iii, Merge. Mantle region is indicated by asterisk. D, Transplanted early NSC progeny sequester outside developing brain. By E13.5, primitive NSC rosette-shaped colonies had grown considerably and were now completely outside the brain but beneath the ectoderm. Merge shows bright field of E13.5 brain section and GFP channel, with mantle region indicated by asterisk.

These behaviors observed in culture account for similar sorting events when cells are introduced into the tissues of the developing conceptus. We conclude that as ESCs transition to primitive NSCs, they retain an adhesive character that is compatible with the early murine ICM when introduced into the blastocyst in vivo. Primitive NSCs then transition into an adhesion profile that is compatible with the early neural tube, but not the preimplan- 
A.
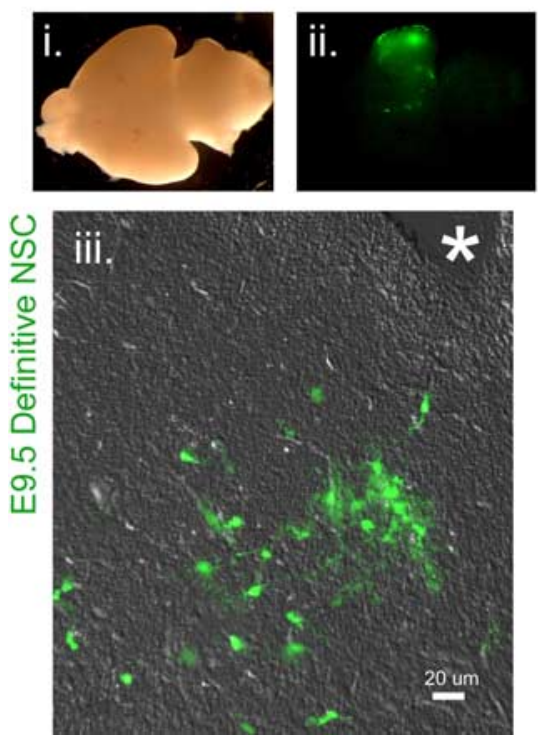

B.
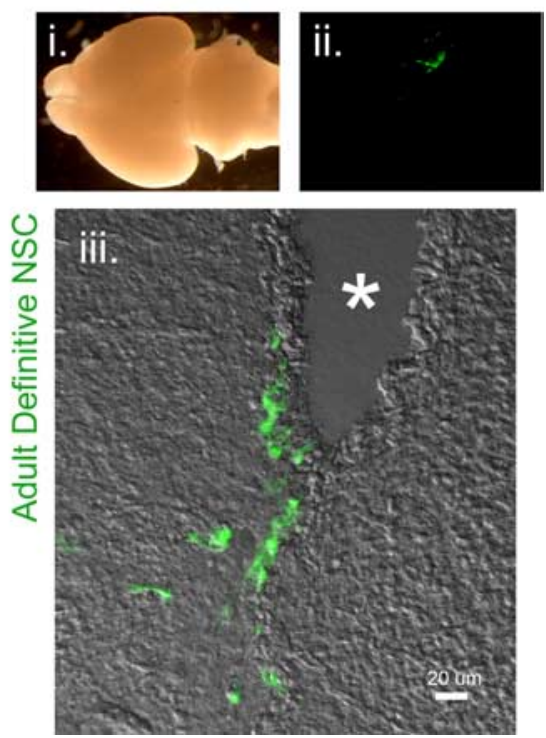

Figure $6 \boldsymbol{A}$, Transplanted E9.5-derived NSCs persist in the brain. E9.5 NSC-derived cells (green) remain in the developing brain, after transplant into the $\mathrm{E9} .5$ telencephalon, and are widespread at P1. $\boldsymbol{i}$, Whole mount of brain. $\boldsymbol{i i}$, Regions derived from GFP $(+$ ) E9.5 definitive NSCs. iii, In contrast to ES-derived primitive NSCS, which were no longer present at this time point, cells remain in or next to ventricles in a scattered manner at P1, as shown in merge of bright field and GFP channel. Note the differentiated morphology of the transplanted cells. Ventricles are indicated by asterisks in sections. $\boldsymbol{B}$, Transplanted adult-derived NSCs persist in the brain. Adult NSC-derived cells (green) are also present at P1, after transplant into the E9.5 telencephalon. $\boldsymbol{i}$, Whole mount of brain. ii, Regions derived from GFP(+ ) adult definitive NSC. iii, Similarly to the E9.5-derived definitive NSCs, the progeny of adult definitive NSCs remain in or next to ventricles and are scattered throughout these regions at $P 1$, as shown in merge of bright field and GFP channel. Similar to the E9.5 NSC progeny, adult NSC progeny also display a differentiated morphology but in fewer cells than the E9.5-derived NSC descendants (see also Fig. $7 A, B$ ). Ventricles are indicated by asterisks in sections.

tation embryo, and become dependent on exogenous FGF. Such cells finally transition in the adult to a loosely bound profile that appears to be less adherent with the early neural tube or with progeny of E9.5-derived NSCs but remains FGF dependent. These adhesive changes correlate to growth factor dependence alterations in the primitive NSC to definitive NSC transition, but adhesive changes between E9.5-derived definitive NSCs and adult-derived definitive NSCs do not seem to correlate with any alterations in growth factor dependence.

We have observed a sphere-within-sphere configuration arising between cocultures of adult NSC progeny and ESCs, as well as adult NSCs and E9.5-derived NSC progeny. Such sorting behaviors are thought to be a result of (1) the two different cell types expressing different levels of the same cadherin; (2) the central cells expressing an additional cadherin not present in the surrounding cells; or (3) heterophilic binding between two different cadherins, which allows the cell types to adhere but which is weaker than the homophilic binding of the central cells. Any of these three possibilities accounts for the increased binding stability of the central cells that leads to this outcome (Foty and Steinberg, 2005); however, our analysis favors the coexpression of $\mathrm{N}$ and P-cadherin that drives ESCs and E9.5-derived NSCs into the center of aggregates when these are cultured with adult NSCs. However, the complete sorting out of primitive NSC progeny from E9.5 dissected germinal zone cells, adult NSCs, and the embryonic brain when introduced into the E9.5 embryo can either be explained in a similar manner by relative adherence or, alternatively, by relative adherence and repulsion. Primitive NSC progeny and the other cell types might be actively repulsed by one another. The ephrin/Eph receptor signaling pathway could be responsible for the active movement of primitive NSC progeny away from the E9.5-derived or adult cells, because such interactions are known to produce repulsive interactions (Pasquale, 2005). We cannot rule out this possibility at this time, although if such repulsion were the only factor, one might expect complete separation between primitive NSC progeny and the E9.5 or adult cells after a $24 \mathrm{~h}$ in vitro cell coculture. Because this complete separation was not observed, it seems reasonable to assume there is some low-level adherence between these cells. Such low adherence would compete weakly against a stronger repulsion that would separate these populations but maintain some level of association between them leading to a sorting out of these populations.

The frequency of adult NSC contribution to non-neural tissues in blastocyst chimeras is exceedingly low: 6 per $600 \mathrm{em}$ bryos assayed (Clarke et al., 2000). Aggregations of adult neural and retinal SC colonies with morulae demonstrated a sorting-out phenomenon caused by intercellular adhesive discrepancies, which preempt any possibility of chimeric contribution by aggregated cells. The failure to replicate (Tropepe et al., 2001; D'Amour and Gage, 2003; Greco et al., 2004) initial reports (Clarke et al., 2000) of adult NSC plasticity may be a result of our observation that only $<3 \%$ of adult cells actually associate with the ICM. Thus, these studies, which have performed $<100$ blastocyst injections, would have only undertaken less than three actual blastocyst assays to support their conclusions, and moreover, it is unclear whether these assays have tested NSCs themselves, which are a rare population, or simply the progenitors arising from NSCs. It was therefore not clear whether such cells did not possess pluripotency or were simply unable to colonize the inner cell mass of the blastocyst.

The overexpression of relevant cadherins, in this case E-cadherin, demonstrates that the modification of cell-cell adhesion is successful in associating NSCs with the cells of inner cell mass. Whereas control adult NSCs were cleared from the blastocyst after overnight incubation (such cells either died or were sorted outside of the trophoblast layer), 37\% of E-cadherintransfected adult NSCs associated with the ICM of murine blastocysts. Nonetheless, this increased association of NSC progeny did not alter their baseline characteristics, and thus adult E-cadherin-overexpressing cells continued to express the neural markers nestin or GFAP. Similarly, embryoid body cocultures of E-cadherin-overexpressing NSC progeny and ESC progeny demonstrated that NSCs only generate nestin $(+)$ and $\operatorname{GFAP}(+)$ cell types typical of NSCs under these conditions. Despite hundreds of blastocysts attempted, and despite the successful association of such cells with the ICM or central regions of embryoid bodies through the forcible expression of E-cadherin, we were unable to find a single instance of the pluripotency of adult NSCs. This suggests that the alteration of adhesion characteristics is independent of cellular potency in these cells and that such cells cannot be induced to display pluripotency by association with pluripotent cell types. These results are consistent with previous data (Greco 


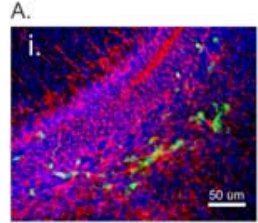

E9.5 NSC + Nestin

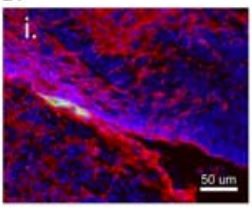

Adult NSC + Nestin

C.

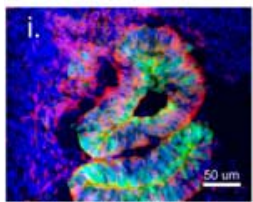

Primitive-NSC + Nestin

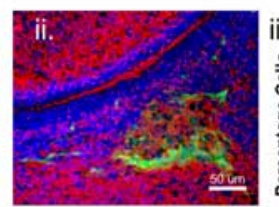

E9.5 NSC + $\beta$-III-Tubulin
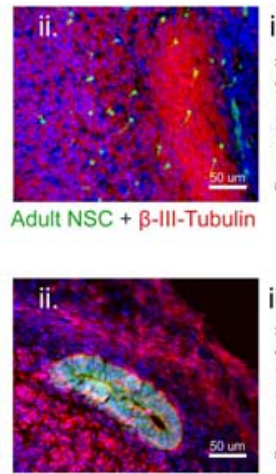

Primitive-NSC + $\beta$-III-Tubulin
Adult NSC + $\beta$-III-Tubulin
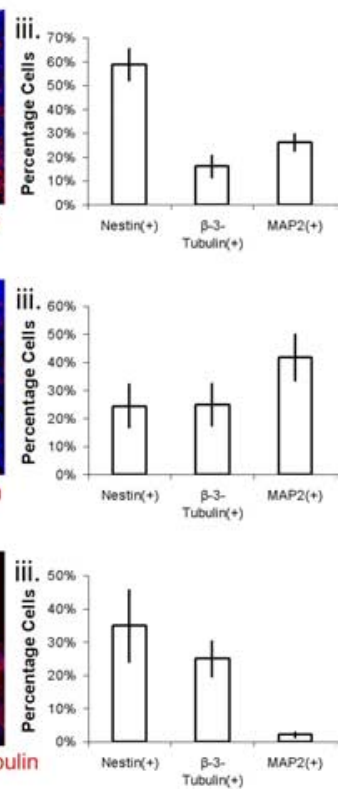

Figure $7 \quad \boldsymbol{A}$, E9.5-derived NSC progeny contribute to the brain. $\boldsymbol{i}, \boldsymbol{i i}, \mathrm{P} 1$ sections show that $\mathrm{GFP}(+)$ E9.5 NSCs transplanted into the E9.5 telencephalon make both nestin $(+)$ cells (i) and $\beta$-3-tubulin $(+)$ cells (ii) after transplantation into the E9.5 brain. Transplanted cells are shown in green, markers of interest are in red, nuclei are counterstained with Hoechst (blue), and yellow indicates double-labeled cells. iii, Sections sampled ( $n=3$ pups) were scored for total number of marked cells as a percentage of the total number of transplanted cells. The E9.5derived NSC progeny included substantial numbers of nestin, $\beta$-3-tubulin, and MAP2-positive cells. $\boldsymbol{B}$, Adult-derived NSC progeny contribute to the brain. $\boldsymbol{i}$, $\boldsymbol{i}$, Adult GFP $(+)$ NSCs also give rise to nestin $(+)$ cells $(\boldsymbol{i})$ or $\beta$-3-tubulin $(+)$ cells (ii) after transplantation into the E9.5 telencephalon. Transplanted cells are shown in green, markers of interest are in red, nuclei are counterstained with Hoechst (blue), and yellow indicates double-labeled cells. iii, Sections sampled ( $n=3$ pups) were scored for total number of marked cells as a percentage of the total number of transplanted cells. Similarly to the E9.5-derived NSCS, the adult-derived NSC progeny included substantial numbers of nestin, $\beta$-3-tubulin, and MAP2-positive cells. C, Primitive NSCs possess neural potency but do not contribute to the brain. $\boldsymbol{i}$, $\boldsymbol{i}$, After transplantation into the E9.5 telencephalon, sections of GFP( + ) primitive NSC colonies in E13.5 embryos show the presence of neural markers, nestin $(+)(\boldsymbol{i})$, and $\beta$-3-tubulin( + ) (ii). Transplanted cells are shown in green, markers of interest are in red, nuclei are counterstained with Hoechst (blue), and yellow indicates double-labeled cells. The rosettes shown were sorted outside of the developing brain. iii, Sections were sampled ( $n=3$ embryos) for total number of marked cells as a percentage of the total number of transplanted cells. The primitive NSC progeny included nestin and $\beta$-3-tubulin-positive cells, demonstrating that the founder cells retain neural potency in vivo even as they are sorted outside neural tissues. Note that lower proportions of MAP2 $(+)$ cells are observed arising from these transplanted cells than E9.5- and adult-derived NSCs.

et al., 2004) demonstrating that neural cells retain a neural phenotype despite introduction into the early embryo (D'Amour and Gage, 2003; Greco et al., 2004). We conclude that adhesionmediated association of NSCs with pluripotent ESCs is insufficient to alter the fate of NSC progeny.

Cell-sorting behaviors were then shown to be critical for the contribution of competent cells within transplanted brain re- gions. Primitive NSCs were unable to contribute to the murine brain after transplantation into the telencephalic ventricles of E9.5 embryos because they were sorted from within the germinal regions through the mantle regions and then to the outside of the brain proper, at time points as early as E12.5 to E13.5: 48-72 h after transplantation. This is unusual, because the primitive NSCs possess the competency to contribute to the embryonic brain, when aggregated with morula, and have demonstrated the ability to form neurons and glial cells in differentiation conditions in vitro (Tropepe et al., 2001). Indeed, it is likely that these neuralcompetent cells passed through the ventricular zone compartment or niche in which endogenous NSCs were located during their cell-sorting journey within the brain. Such results are reminiscent of cadherin mutations in development, which have been shown to cause competent cells to fail in contributing the appropriate cells within tissues and instead to form rosettes, because of an adhesion failure during organogenesis (Kostetskii et al., 2001). Conversely, definitive NSC colonies derived from the E9.5 telencephalon and the adult subventricular zone, both of which sort randomly with E9.5 dissected germinal zone cells, were both found to contribute both nestin-positive and neuronal progeny when introduced into the E9.5 telencephalic ventricle. These data show that cell sorting and compartmentalization play a role in cellular contribution, independent of a cell's ability to produce differentiated progeny.

Nevertheless, adult definitive NSC progeny produced fewer cell descendants than E9.5 definitive NSC progeny after transplantation in the E9.5 brain. In support of this, it was also noted that adult NSC progeny contributed to the murine brain at a lower frequency than the E9.5 progeny. We interpret this discrepancy in chimeric contribution to result from sorting behaviors observed in aggregates, which demonstrate that E9.5 NSC progeny are more tightly adherent than those produced by adult NSCs, perhaps enabling the E9.5 progeny to maintain a presence in the embryonic telencephalon. Similar adhesive properties have been demonstrated to bias cellular contribution in cells taken from rostral versus caudal regions, when assayed in E15 embryonic chimeras (Olsson et al., 1998). Because we observed the sphere-within-sphere configuration arising between mixtures of the E9.5- and adult-derived NSC descendants, it is possible that such biases are a result of higher levels of N-cadherin in E9.5 NSCs and their progeny relative to adult NSCs and theirs or of the additional presence of cell adhesion molecules in E9.5 NSC descendants versus those from adult NSCs.

It is clear that compatible cell-cell adhesion phenomena may confound SC transplantation assays, by precluding cellular contribution, and for this reason chimera assays should be interpreted carefully before conclusions regarding cell potency can be established. Our experiments further demonstrate fundamental changes in adherence in cells of the NSC lineage during development, suggesting an evolving compartmentalization of the SC niche during neurogenesis that does not necessarily correspond

Table 4. Transplantations into E9.5 telencephalon

\begin{tabular}{|c|c|c|c|c|}
\hline & $\begin{array}{l}\text { Number of E10.5 embryos } \\
\text { with donor cells present }\end{array}$ & $\begin{array}{l}\text { Number of E12.5 embryos } \\
\text { with donor cells present }\end{array}$ & $\begin{array}{l}\text { Number of E13.5 embryos } \\
\text { with donor cells present }\end{array}$ & $\begin{array}{l}\text { Number of P1 pups with } \\
\text { donor cells present }\end{array}$ \\
\hline Early Lif/FGF-dependent NSCS & $12 / 30$ & $10 / 32^{a}$ & $0 / 9$ & Not determined \\
\hline E9.5-derived NSCs & $11 / 13$ & $10 / 23$ & Not determined & $10 / 14$ \\
\hline Adult-derived NSCs & $6 / 7$ & $4 / 21$ & Not determined & $3 / 16$ \\
\hline
\end{tabular}

E9.5- and adult-derived NSC progeny contribute to the brain, whereas primitive NSC progeny do not. In contrast to primitive NSCS, E9.5 and adult definitive NSCs persist after injection into the telencephalic ventricle of E9.5 host embryos. Neither E9.5- or adult-derived NSC progeny formed rosettes or were sorted outside the brain proper. Surprisingly, the primitive NSCs, which possess the potency to contribute to all germ layers in blastocyst chimeras, completely fail to contribute to the E9.5 brain and are sorted outside of the brain between E12.5 and E13.5.

${ }^{a}$ Positive chimerism scored is attributable to the presence of rosettes/colonies of transplanted cells in mantle regions only. 
to changes in NSC growth factor responsiveness or NSC progeny differentiation.

\section{References}

Alvarez-Dolado M, Pardal R, Garcia-Verdugo JM, Fike JR, Lee HO, Pfeffer K, Lois C, Morrison SJ, Alvarez-Buylla A (2003) Fusion of bone-marrowderived cells with Purkinje neurons, cardiomyocytes and hepatocytes. Nature 425:968-973.

Bjornson CR, Rietze RL, Reynolds BA, Magli MC, Vescovi AL (1999) Turning brain into blood: a hematopoietic fate adopted by adult neural stem cells in vivo. Science 283:534-537.

Brazelton TR, Rossi FM, Keshet GI, Blau HM (2000) From marrow to brain: expression of neuronal phenotypes in adult mice. Science 290:1775-1779.

Chiasson BJ, Tropepe V, Morshead CM, van der Kooy D (1999) Adult mammalian forebrain ependymal and subependymal cells demonstrate proliferative potential, but only subependymal cells have neural stem cell characteristics. J Neurosci 19:4462-4471.

Clarke DL, Johansson CB, Wilbertz J, Veress B, Nilsson E, Karlstrom H, Lendahl U, Frisen J (2000) Generalized potential of adult neural stem cells. Science 288:1660-1663.

D'Amour KA, Gage FH (2003) Genetic and functional differences between multipotent neural and pluripotent embryonic stem cells. Proc Natl Acad Sci USA 100 [Suppl 1]:11866-11872.

Dang SM, Kyba M, Perlingeiro R, Daley GQ, Zandstra PW (2002) Efficiency of embryoid body formation and hematopoietic development from embryonic stem cells in different culture systems. Biotechnol Bioeng 78:442-453.

Edelman GM (1984) Cell adhesion and morphogenesis: the regulator hypothesis. Proc Natl Acad Sci USA 81:1460-1464.

Foty RA, Steinberg MS (2005) The differential adhesion hypothesis: a direct evaluation. Dev Biol 278:255-263.

Greco B, Low HP, Johnson EC, Salmonsen RA, Gallant J, Jones SN, Ross AH, Recht LD (2004) Differentiation prevents assessment of neural stem cell pluripotency after blastocyst injection. Stem Cells 22:600-608.

Herrera DG, Garcia-Verdugo JM, Alvarez-Buylla A (1999) Adult-derived neural precursors transplanted into multiple regions in the adult brain. Ann Neurol 46:867-877.

Hitoshi S, Alexson T, Tropepe V, Donoviel D, Elia AJ, Nye JS, Conlon RA, Mak TW, Bernstein A, van der Kooy D (2002) Notch pathway molecules are essential for the maintenance, but not the generation, of mammalian neural stem cells. Genes Dev 16:846-858.

Hitoshi S, Seaberg RM, Koscik C, Alexson T, Kusunoki S, Kanazawa I, Tsuji S, van der Kooy D (2004) Primitive neural stem cells from the mammalian epiblast differentiate to definitive neural stem cells under the control of Notch signaling. Genes Dev 18:1806-1811.

Inoue T, Tanaka T, Takeichi M, Chisaka O, Nakamura S, Osumi N (2001) Role of cadherins in maintaining the compartment boundary between the cortex and striatum during development. Development 128:561-569.

Jiang Y, Jahagirdar BN, Reinhardt RL, Schwartz RE, Keene CD, OrtizGonzalez XR, Reyes M, Lenvik T, Lund T, Blackstad M, Du J, Aldrich S, Lisberg A, Low WC, Largaespada DA, Verfaillie CM (2002) Pluripotency of mesenchymal stem cells derived from adult marrow. Nature 418:41-49.

Kostetskii I, Moore R, Kemler R, Radice GL (2001) Differential adhesion leads to segregation and exclusion of N-cadherin-deficient cells in chimeric embryos. Dev Biol 234:72-79.

Krause DS, Theise ND, Collector MI, Henegariu O, Hwang S, Gardner R, Neutzel S, Sharkis SJ (2001) Multi-organ, multi-lineage engraftment by a single bone marrow-derived stem cell. Cell 105:369-377.

Kubo A, Shinozaki K, Shannon JM, Kouskoff V, Kennedy M, Woo S, Fehling HJ, Keller G (2004) Development of definitive endoderm from embryonic stem cells in culture. Development 131:1651-1662.

Larue L, Ohsugi M, Hirchenhain J, Kemler R (1994) E-cadherin null mutant embryos fail to form a trophectoderm epithelium. Proc Natl Acad Sci USA 91:8263-8267.

Matsunami H, Takeichi M (1995) Fetal brain subdivisions defined by Rand E-cadherin expressions: evidence for the role of cadherin activity in region-specific, cell-cell adhesion. Dev Biol 172:466-478.
Mezey E, Chandross KJ, Harta G, Maki RA, McKercher SR (2000) Turning blood into brain: cells bearing neuronal antigens generated in vivo from bone marrow. Science 290:1779-1782.

Morshead CM, Reynolds BA, Craig CG, McBurney MW, Staines WA, Morassutti D, Weiss S, van der Kooy D (1994) Neural stem cells in the adult mammalian forebrain: a relatively quiescent subpopulation of subependymal cells. Neuron 13:1071-1082.

Nagy A, Gertsenstein M, Vintersten K, Behringer R (2002) Manipulating the mouse embryo: a laboratory manual. Cold Spring Harbor, NY: Cold Spring Harbor Laboratory.

Neganova IE, Sekirina GG, Eichenlaub-Ritter U (2000) Surface-expressed E-cadherin, and mitochondrial and microtubule distribution in rescue of mouse embryos from 2-cell block by aggregation. Mol Hum Reprod 6:454-464.

Nose A, Nagafuchi A, Takeichi M (1988) Expressed recombinant cadherins mediate cell sorting in model systems. Cell 54:993-1001.

Olsson M, Campbell K, Turnbull DH (1997) Specification of mouse telencephalic and mid-hindbrain progenitors following heterotopic ultrasound-guided embryonic transplantation. Neuron 19:761-772.

Olsson M, Bjerregaard K, Winkler C, Gates M, Bjorklund A, Campbell K (1998) Incorporation of mouse neural progenitors transplanted into the rat embryonic forebrain is developmentally regulated and dependent on regional and adhesive properties. Eur J Neurosci 10:71-85.

Pasquale EB (2005) Eph receptor signalling casts a wide net on cell behaviour. Nat Rev Mol Cell Biol 6:462-475.

Redies C (2000) Cadherins in the central nervous system. Prog Neurobiol 61:611-648.

Reynolds BA, Tetzlaff W, Weiss S (1992) A multipotent EGF-responsive striatal embryonic progenitor cell produces neurons and astrocytes. J Neurosci 12:4565-4574.

Shimamura K, Takeichi M (1992) Local and transient expression of E-cadherin involved in mouse embryonic brain morphogenesis. Development 116:1011-1019.

Slevin JC, Byers L, Gertsenstein M, Qu D, Mu J, Sunn N, Kingdom JC, Rossant J, Adamson SL (2006) High resolution ultrasound-guided microinjection for interventional studies of early embryonic and placental development in vivo in mice. BMC Dev Biol 6:10.

Steinberg MS, Takeichi M (1994) Experimental specification of cell sorting, tissue spreading, and specific spatial patterning by quantitative differences in cadherin expression. Proc Natl Acad Sci USA 91:206-209.

Takeichi M (1995) Morphogenetic roles of classic cadherins. Curr Opin Cell Biol 7:619-627.

Terada N, Hamazaki T, Oka M, Hoki M, Mastalerz DM, Nakano Y, Meyer EM, Morel L, Petersen BE, Scott EW (2002) Bone marrow cells adopt the phenotype of other cells by spontaneous cell fusion. Nature 416:542-545.

Tropepe V, Sibilia M, Ciruna BG, Rossant J, Wagner EF, van der Kooy D (1999) Distinct neural stem cells proliferate in response to EGF and FGF in the developing mouse telencephalon. Dev Biol 208:166-188.

Tropepe V, Coles BL, Chiasson BJ, Horsford DJ, Elia AJ, McInnes RR, van der Kooy D (2000) Retinal stem cells in the adult mammalian eye. Science 287:2032-2036

Tropepe V, Hitoshi S, Sirard C, Mak TW, Rossant J, van der Kooy D (2001) Direct neural fate specification from embryonic stem cells: a primitive mammalian neural stem cell stage acquired through a default mechanism. Neuron 30:65-78.

Wagers AJ, Sherwood RI, Christensen JL, Weissman IL (2002) Little evidence for developmental plasticity of adult hematopoietic stem cells. Science 297:2256-2259.

Wang X, Willenbring H, Akkari Y, Torimaru Y, Foster M, Al Dhalimy M, Lagasse E, Finegold M, Olson S, Grompe M (2003) Cell fusion is the principal source of bone-marrow-derived hepatocytes. Nature 422:897-901.

Wurmser AE, Nakashima K, Summers RG, Toni N, D'Amour KA, Lie DC, Gage FH (2004) Cell fusion-independent differentiation of neural stem cells to the endothelial lineage. Nature 430:350-356.

Ying QL, Nichols J, Evans EP, Smith AG (2002) Changing potency by spontaneous fusion. Nature 416:545-548. 